Running Head: PUBERTY PROGRAMS AND POLICY

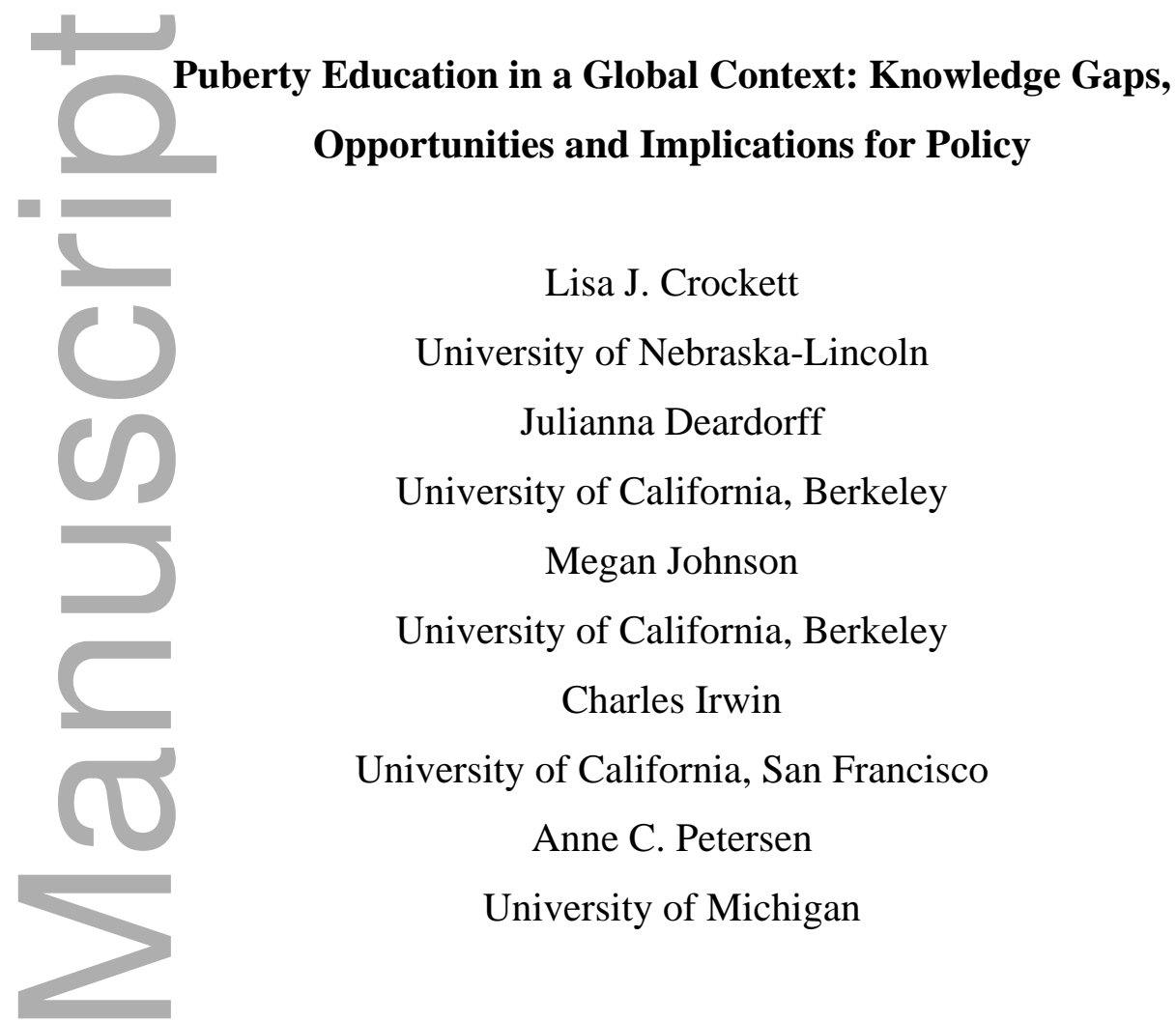

Submitted to the Journal of Research on Adolescence as part of a proposed special section on "The New Biobehavioral Developmental Science of Puberty." Correspondence can be directed to L. Crockett, 315 Burnett Hall, University of Nebraska- Lincoln, Lincoln, NE, 68588-0308, ecrockett1@unl.edu.

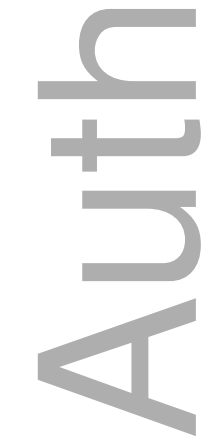

This is the author manuscript accepted for publication and has undergone full peer review but has not been through the copyediting, typesetting, pagination and proofreading process, which may lead to differences between this version and the Version of Record. Please cite this article as doi: $\underline{10.1111 / \text { jora. } 12452}$

This article is protected by copyright. All rights reserved 
Article type : Special Section-Issue

Abstract

Youth programs and policies provide opportunities for institutions and societies to support healthy adolescent development. Puberty education programs are universally important, as they provide crucial knowledge and skills to help youth and their caregivers navigate the physical, emotional, and interpersonal changes of puberty with positive outcomes. However, few puberty programs have been rigorously evaluated, resulting in a lack of evidence-based knowledge and practice in this area. This review examines the status of research on puberty education and related programs and draws on the broader intervention literature and recent research findings on adolescence to identify program features that might improve program effectiveness. Implications for policy are also discussed. The need for rigorous program evaluation is emphasized throughout.

\section{Puberty Education in a Global Context: Knowledge Gaps, Opportunities and Implications for Policy}

Puberty is a universal experience with profound implications for adolescents' physical and emotional functioning as well as their long-term sexual and reproductive health. As a result, programs that educate young people on the changes they are experiencing or foster positive attitudes and healthy practices related to pubertal changes are important globally. Such programs provide crucial knowledge and skills to help youth navigate the physical, emotional, and interpersonal changes of puberty with positive outcomes. Yet, despite decades of scientific research on diverse aspects of puberty, puberty education programs have received relatively little 
attention. Few programs have been scientifically evaluated, and the dearth of rigorous evaluation studies impedes the development of effective, evidence-based programs and policies.

Puberty programs refer to education on pubertal development that is embedded in health or sexuality curricula as well as free-standing interventions targeting attitudes and behaviors associated with specific pubertal changes. In this paper, we use an interdisciplinary lens to examine the current status of evidence regarding puberty programs, and related policies, and make recommendations for future research and practice. The paper also incorporates recent findings on adolescent development. Our goal is not to provide an exhaustive list of programs or policies or a comprehensive review of effective programs but rather to take stock of the scientific evidence regarding puberty programs and suggest measures to improve education, practice, and policies in the U.S. and globally.

We begin by identifying three general sources of puberty information (puberty instruction within sexual or health education, free-standing puberty intervention programs, and supplemental resources, e.g., websites) and describe the status of scientific knowledge on each one, noting gaps in the knowledge base. Next, we discuss program features thought to characterize effective interventions for youth and discuss their application to puberty education programs. This section is necessarily speculative owing to a paucity of rigorous evaluation studies of puberty programs. We then consider policy issues relevant to puberty programs and end with recommendations for research, programs, and policy. Throughout, we focus primarily on programs in the U.S. but discuss those in other countries to provide a broader perspective and a point of contrast.

\section{Sources of Puberty Information}

Formal instruction on puberty is typically delivered as part of sexual education curricula in schools or other community settings, or through freestanding intervention programs that target specific attitudes, skills, or behaviors related to pubertal changes (e.g., positive attitudes, safe hygiene practices). In addition, information on puberty is available informally from a variety of supplemental sources (e.g., websites, popular books, and health care providers) that may be accessed (or not) depending on individual preference. (Other informal sources of information on puberty such as family members and peers are not considered here.) A key issue regarding these diverse sources is that puberty information is often embedded in programs and content targeting related topics such as sexual education, pregnancy prevention, and HIV/STD prevention where puberty is not the primary focus. The fact that information on puberty tends to be delivered as 
part of other programs, rather than being focal, creates challenges for determining where puberty content exists and the effectiveness with which it is delivered.

\section{Puberty Education Within Sexual Education}

Puberty education in the U.S. In the U.S., classroom-based instruction on puberty is regularly delivered in schools, where it is often embedded in health education curricula, typically as part of sexual education. Because schools have the capacity to reach a large number of youth, school-based instruction is a critical opportunity for learning about puberty. However, because puberty content is frequently covered in sexual or health education classes and not examined separately, the prevalence and scope of puberty instruction is difficult to assess, creating an important gap in the knowledge base on puberty education.

Indeed, few surveys have examined school-based puberty instruction across the U.S., and those that do consider puberty as a component of sexual education. As a result, much of our information on puberty education comes from surveys of sexual education. In an early survey of U.S. elementary schools, $72 \%$ of fifth- and sixth-grade public school teachers reported that sexual education was taught in their school at fifth and/or sixth grade, and $90 \%$ of those who taught sexual education said that they covered puberty (Landry, Singh, \& Darroch, 2000). These numbers imply that $65 \%$ of public elementary schools included some type of puberty instruction in grades 5 or 6 . More recent information comes from the School Health Policies and Practices Study (SHPPS) a national survey of U.S. schools conducted periodically by the Centers for Disease Control and Prevention (CDC). According to data from the 2014 survey, $40 \%$ of schools taught "human development issues" as part of their required human sexuality instruction, including $21 \%$ of elementary schools, $45 \%$ of middle schools, and $66 \%$ of high schools (CDC, 2015). Although "human development issues" are not defined in the report, the examples given (reproductive anatomy, puberty) suggest puberty-related content. Insofar as this represents puberty instruction, it appears that less than half of U.S. primary and secondary schools require puberty education in any given year (elective courses were not reported). Moreover, most schools allow parents to opt out of sexuality instruction for their children (Guttmacher Institute, 2018), so some youth may not receive puberty instruction even when it is available. It is also noteworthy that most of the required instruction occurs in middle school and high school. Since the average age of pubertal onset (in terms of secondary sex characteristics) is age 8 or 9 for girls and 9 or 10 for boys, depending on race (Herman-Giddens et al., 1997; Herman-Giddens et al., 
2012), puberty instruction that starts in middle school is likely too late to be fully effective, especially for youth who mature early relative to their peers.

In the CDC (2015) and Landry et al. (2000) studies, details on the scope of puberty instruction (e.g., which topics were covered) are missing, so we do not know whether coverage was limited to biological changes and reproduction or included discussion of emotional and social changes. There is also a lack of information concerning whether individual differences in pubertal development (e.g., timing of maturation) or in the experience of puberty are addressed. The lack of clarity extends to how much time is devoted to puberty-related topics. According to one estimate, the median amount of time devoted to sexual education in the preceding year was 3.1 hours in elementary schools, 6 hours in middle schools, and 8.1 hours in high schools (Future of Sexual Education, 2012). As puberty is only one aspect of sexual education, the amount of time devoted to puberty instruction was probably less than the hours reported above.

U.S.-based organizations, such as Planned Parenthood, also offer group-based puberty instruction in schools or other in community settings as part of sexual education classes (e.g., https://www.plannedparenthood.org/learn/for-educators/what-sex-education). Although sexual education is the primary goal, Planned Parenthood considers human development (including puberty) to be part of comprehensive sexual education (Braeken, Shand, \& de Silva, 2006). Unfortunately, data on puberty education is not reported separately. For example, the annual report for 2016-2017 states that Planned Parenthood provided sexual education or outreach to 1.5 million people (Planned Parenthood Federation, 2017), but it does not break these numbers down by age or indicate how many individuals received puberty instruction as part of sexual education. Similarly, information on puberty (e.g., on reproductive anatomy) often is incorporated in intervention programs designed to reduce risky sexual behavior, pregnancy, or transmission of STIs and HIV/AIDS). However, because these programs focus on behavioral outcomes, rather than on understanding and adapting to pubertal changes (DiClemente, Salazar, \& Crosby, 2007; Ross, Dick, \& Ferguson, 2006), pubertal content may be limited.

Puberty education in other countries. Sexual education is mandatory in most nations of the European Union, but content and quality vary widely by country and school (Baumont \& Maguire, 2013). Although published reports do not clearly document the provision of puberty content, sexuality education is typically taught in biology classes (Parker, Wellings, \& Lazarus, 2009; Wellings \& Parker, 2006), suggesting there is attention to biological aspects of puberty but 
perhaps not to emotional or psychosocial aspects. Puberty education in majority world countries was the subject of a recent report published by the United Nations Educational, Scientific and Cultural Organization (UNESCO; Kettaneh, Pulizzi, \& Todesco, 2014), which reviewed promising educational programs but did not attempt to document the prevalence of puberty education globally. The report draws on a prior review of sexual education curricula in 10 African counties (Population Council, 2012) which indicated that most sexual education curricula covered puberty but typically focused on puberty as a biological process without considering associated psychological aspects or changes in social context (e.g., stigma, sexual harassment). Furthermore, the report suggested that coverage of puberty-related topics such as reproductive anatomy/physiology and reproduction was weak or missing in more than half of the curricula, and there were further weaknesses in regard to affective learning and critical thinking. The authors concluded that "most curricula reviewed lack the minimum 'package' of content and approach that is likely to achieve meaningful results" (p. 8). Thus, while there is evidence that puberty content is taught in a large number of countries as part of sexual or health education, data on its prevalence and scope are sparse. Moreover, the puberty content offered may be limited in scope and poor in quality.

Program effectiveness. A second major gap in our understanding of school-based puberty education relates to its effectiveness. Although students' knowledge of puberty can be assessed through tests and surveys, formal evaluations of classroom-based puberty education programs are rare in the scientific literature. A PsycInfo search with "pubert*" + "education*" as keywords yielded 60 publications, but only six articles described specific programs and five reported some form of evaluation data (e.g., pre- to post-program comparisons; randomized clinical trials). Only two of the evaluated programs were based in North America; the rest were in majority world countries. Most were free-standing intervention programs rather than puberty education delivered as part of the regular school curriculum. As suggested earlier, the dearth of research on puberty education in schools most likely means that puberty content is provided as part of sexual or health education and is not evaluated separately. This situation presents a stark contrast to sexual education programs which have been extensively evaluated in the U.S. and other countries (e.g., Kirby, Laris, \& Rolleri, 2007, Kirby \& Landis, 2009; Santelli, 2017). As noted earlier, because the primary goals of sexual education are to reduce risky sexual behavior, 
teen pregnancy and STIs, the outcomes evaluated reflect those goals rather than knowledge, attitudes, experiences, or practices related to puberty.

Published evaluations of puberty education programs in the majority world are also rare, even though puberty education is starting to be integrated into national health education curricula. One study evaluated a life skills program for HIV prevention used by schools in South Africa (Peltzer \& Promtussananon, 2003). Exposure to the life skills curriculum in school was positively associated with puberty/body knowledge among students. The UNESCO report (Kettaneh et al., 2014) identified other promising programs, but few had been systematically evaluated. Overall, although puberty content may be delivered in a broad array of educational programs globally, evidence concerning its effectiveness is relatively sparse and largely invisible in the research literature.

\section{Free-Standing Puberty Interventions}

Our literature search uncovered very few published evaluations of free-standing puberty programs conducted in North America or Europe. One was an internet-based program that sought to improve puberty knowledge, body image, and self-esteem among sixth grade students in the U.S. (Cousineau et al., 2010). Six health-related topics were covered including puberty, nutrition, physical activity, self-esteem, and peer relations. To be engaging for youth, the program was framed as a mystery story in which a carnival worker disappears and his sister and friends try to find him. Youth "interacted" with teenage carnival workers, uncovered clues to the missing teen's location, and received information about each health topic through quizzes, games, and videos. A pilot study yielded promising results (Watt, Rancourt, Cousineau, \& Franko, 2005), but a subsequent randomized controlled trial indicated no significant overall effects for any of the three outcomes. However, there were program effects for specific subgroups of youth. Participants in the intervention group who had already started puberty (versus those who had not) showed significantly more improvement in perceived physical appearance and global self-esteem compared to controls. Furthermore, girls in the intervention group increased in self-esteem significantly more than those in the control group, whereas boys in the intervention group decreased in global self-esteem compared to control boys, whose self-esteem improved. These findings point to the potential benefits of internet-based puberty programs tailored to a youth's gender and pubertal status. 
Another notable study was an educational intervention conducted in Sweden with the aim of improving attitudes towards menstruation among 12-year-old girls (Rembeck \& Gunnarsson, 2004). All girls received standard puberty education in school; in addition those assigned to the "active intervention" group participated in a two-hour session led by the school nurse and a nurse-midwife. The active intervention focused on open-ended discussion of girls' thoughts and questions about the transition from girl to woman and included discussion of the menstrual cycle, activities during menstruation, and female external genitalia; it also incorporated concrete teaching aids such as a model of the uterus and various kinds of tampons and sanitary pads. Passive learning methods (e.g., watching videos) and lecture format were avoided. For girls ( $\mathrm{n}=$ 38) who experienced menarche between the pre- and post-test survey those in the active intervention group showed more improvement in attitudes towards menarche than those in the standard intervention group, whose attitudes worsened. Girls who remained pre-menarcheal did not show this effect, and girls who were already post-menarcheal benefited more from the standard intervention. These results underscore the value of interventions tailored to youth in particular stages of pubertal development as well as the value of an active learning approach for some girls. It is noteworthy that such targeted interventions can be beneficial even in countries with a well-developed school-based health curriculum.

Lastly, a Canadian study evaluated the effects of an online module designed to improve knowledge levels and comfort regarding pubertal examinations among pediatric residents (Ens, Janzen, \& Palmert, 2017). According to a needs assessment, about half of the sample reported discomfort about introducing the pubertal exam, a lack of confidence concerning the exam, and attempts to avoid giving the exam. A learning module was developed to address those issues, and a randomized assessment of the module indicated that, compared to the control group, the intervention group improved more in knowledge and confidence regarding the pubertal exam.

Puberty programs in the majority world. In low- and middle-income countries, puberty programs often focus narrowly on menstruation. Search terms such as "menstrual health" or "menstrual hygiene" yield studies of programs conducted in Africa or Asia where program content focuses on education about menstruation and the provision of sanitary products (e.g., Fakhri, Hamzehgardeshi, Golchin, \& Komili, 2012; Montgomery, Hennegan, Dolan, Wu, Steinfield, \& Scott, 2016; Phillips-Howard et al., 2016; Shah, Nair, Shah, Modi, Desai, \& Desai, 2013; Sommer \& Sahin, 2013). Although adequate menstrual hygiene management is taken for 
granted in developed nations, poor menstrual hygiene and stigma around menstruation in developing countries can lead to a host of negative outcomes for girls, including school absence, school drop-out, social exclusion, and reproductive disease (e.g., Chandra-Mouli \& Patel, 2017; Das et al., 2015; Lahme, Stern, \& Cooper, 2016; Mason et al., 2013; Sommer, 2010; Sumpter \& Torondel, 2013).

Program effectiveness. Despite their potential value, few menstrual hygiene programs have been rigorously evaluated. A systematic review of interventions designed to improve menstrual hygiene management (Hennegan \& Montgomery, 2016) identified 28 programs, but only 8 that were evaluated in controlled trials (randomized or unrandomized). Most of these 8 programs delivered puberty or menstrual education, and a few provided girls with sanitary pads or menstrual cups. Information on the educational components was limited in the original articles, and this, along with program differences, reduced study comparability, limiting the conclusions that could be drawn; however, there was some evidence that education was associated with improvements in girls' knowledge, attitudes, and practices. These findings are consistent with other recent studies showing that puberty education programs have a positive effect on girls' knowledge and attitudes about puberty and menstruation (Afsari, Mirghafourv, Valizadeh, Abbasnezhadeh, Galshi, Fatahi, 2017; Hennegan, Dolan, Steinfield, \& Montgomery, 2017; Rani, Sheoran, Kumar, \& Singh, 2016). Overall, there is promising evidence that educational programs targeting menstrual hygiene improve knowledge and hygienic practices, but may fall short on changing related psychosocial and educational outcomes (Hennegan \& Montgomery, 2016; Kuhlmann, Henry, \& Wall, 2017). Despite the number and diversity of programs that exist globally, evaluations of puberty programs are rare, especially rigorous evaluations using randomized controlled trials.

A prominent feature of free-standing menstrual hygiene and puberty education programs in the majority world is that they typically serve girls and not boys. A focus on girls is understandable given the risks that menstruation poses to their health and educational outcomes in many developing countries. However, boys often have misconceptions about pubertal development and menstruation (e.g., Tondare, Chandra, \& Kembhavi, 2011) and would likely benefit from education about their own pubertal changes as well as those occurring in girls. Indeed, the UNESCO report (Kettaneh et al., 2014) recommended that both genders receive puberty education to dispel myths and to facilitate mutual understanding and respect. 


\section{Supplemental Puberty Education Resources}

Apart from school-based education and free-standing educational interventions, adolescents and their parents/caregivers can obtain information on puberty from a variety of sources including the internet, books, and mobile devices. The advantage of these resources is that they are available on demand and can be accessed based on individual needs and interests. Most adolescents in the U.S. have access to the internet and 95\% have access to a smart phone (Pew Research Center, 2013; 2018); virtually all have access to books and print media. In majority world countries, internet access is generally lower than in countries with advanced economies (a median of 54\% among adults compared to 87\%; Pew Research Center, 2016) and varies widely, ranging from $8 \%$ to $76 \%$ of adults across 21 countries (Pew Research Center, 2015). There are opportunities to supplement school-based puberty education with puberty books, online videos and games, and mobile technology (Kettaneh et al., 2014).

Online Resources. The internet is a powerful tool for accessing health-related information, including information on puberty. In the U.S., most adolescents (84\%) have used the internet to find health information (Wartella, Rideout, Montague, Beaudoin-Ryan, \& Lauricella, 2016), and nearly one in five teens (18\%) have sought online information on puberty. Moreover, over one in four (28\%) youth say they have changed their behavior due to health information obtained online, suggesting that such information can be persuasive. Nearly a third of teens ( $31 \%$ percent) visit medical websites for health information, but less reliable sources, such as Facebook, are also used.

A variety of puberty resources for teachers, youth, and parents are available online, ranging from age-based sexual education guidelines that include puberty (e.g., Future of Sex Education Initiative, 2012; National Guidelines Taskforce, 2004) to information on pubertal changes (e.g., https://www.plannedparenthood.org/learn/teens/puberty; https://www.girlshealth.gov/body/index.html; https://kidshealth.org/en/kids/grow/?WT.ac=knav-grow) to videos that present information on pubertal changes or related skills (e.g., how to use a tampon). Online resources for parents offer information on the signs of puberty and what to expect, as well as videos and encouragement to talk with their children about pubertal changes (e.g., http://kidshealth.org/en/parents/talk-about-puberty.html). An advantage of online sources is that they can be accessed as needed, on an individualized basis, and in relative privacy. However, quality varies considerably, and some websites can be challenging to navigate. 
A critical need is to identify sites with accurate information. A national study indicated that when seeking health-related information online, nearly three-fourths of U.S. teenagers use a search engine to get started and half of those youth usually just click the first site that pops up (Wartella et al., 2016). Concerns about accuracy of online information are relevant globally, and the UNESCO report (Kettaneh et al., 2014) cautions that teachers or other adults will need to help youth build skills in searching for and accessing accurate information. Both youth and their parents would benefit from guidance concerning which websites can be trusted to provide accurate, unbiased information on puberty.

Fortunately, this need is starting to be addressed through websites such as www.infoaboutkids.org. Created by a consortium within the American Psychological Association, this website acts as a clearinghouse, providing links to resources on other websites that have been vetted using stringent criteria and are deemed to be science-based and unbiased. Topics address the overlapping areas of Mind/Body/Emotions/Relationships, with puberty listed as one of the topics under the theme of "body." The site has received the international HONcode certification for trustworthy health information on the internet (https://www.hon.ch/HONcode/) and promises to be a valuable resource for parents, educators, and practitioners seeking sciencebased information on puberty.

Mobile technology. Given that youth are already oriented towards garnering information through computer-mediated sources, mobile technology can be used to provide useful information on puberty and nudge healthy decisions. Roughly one-fifth (21 percent) of U.S. adolescents say they have downloaded health-related mobile apps and 7 percent saying they changed their behavior because of using a mobile app (Wartella et al., 2016). Examples might include phone applications such as those used in sexual education (Sheoran, Braun, Gaarde, \& Levine, 2014), menstrual period tracking (McCartney, 2016), or pregnancy applications where a tip or bit of information is given daily (Lupton, 2016). Furthermore, computer games or phone apps could be created that focus on making healthy choices and avoiding puberty pitfalls such as acne, poor body image, or stress.

Puberty books and readers. Youth and their parents may also benefit from books designed to answer their questions about puberty. One endeavor to educate youth has been notable. The Girlology and Guyology books and programs (www.girlology.com) were initiated by an ob-gyn and a pediatrician to fill an unmet need in their patient population. Initially, they 
led small groups of mothers and daughters in conversations about puberty, but when the need outpaced their availability they developed medically-accurate and developmentally-appropriate educational books and community programs that are user friendly to address pubertal development, reproduction, and healthy sexual development in girls and boys. Currently, these books and programs are distributed across the country (the latter are delivered by physicians and educators). However, this endeavor remains a grassroots effort, and widespread dissemination and evaluation are challenging. As a second example, the American Girl series of books, The Care and Keeping of You, (e.g., Natterson, \& Masse, 2013) includes two volumes, one dedicated to pre- and peri-pubertal girls and the other to girls who are slightly older. Both books were written by (or in consultation with) a pediatrician with expertise in girls' puberty. This two-part series is frequently recommended by health providers and parents and is among the most popular puberty books for girls. However, like the Girlology/Guyology books, there is no formal method of tracking their impact on pubertal knowledge for parents and their children. Popular books on puberty are also available for parents (e.g., Greenspan \& Deardorff, 2014).

In some majority world countries, school-based curricula are supplemented by puberty readers - books that address aspects of puberty not covered in classes (e.g., managing menstruation, feeling comfortable with physiological and emotional changes) (Kettaneh, 2014) - but these vary markedly in content and quality, are often designed in response to local issues, and are rarely evaluated. Responses to a puberty reader in Tanzania were positive; girls reported that the book improved their understanding of puberty and enabled them to help other girls as well (Sommer, 2011).

Edutainment and Telenovelas. Edutainment involves using mass media programming to change public attitudes and behavior (Banerjee, LaFerrara, \& Orozco, 2018). Although research on Edutainment is relatively new, rigorous evaluations have shown promising effects on attitudes and behaviors in multiple sectors of public life, including health (DellaVigna \& Ferrara, 2015). Notably, a recent randomized controlled trial in Lagos, Nigeria indicated that watching screenings of the MTV series "Shuga" was associated with increased knowledge of HIV transmission, decreases in the number of concurrent sexual partners, and reduced incidence of STDs (but not increased condom use) among youth 18-25 years of age (Banerjee et al., 2018). Similarly, a survey conducted in South Africa indicated that exposure to mass media education about HIV through television series was positively associated with condom use knowledge, self- 
efficacy, and delayed sexual activity among youth (Peltzer \& Promtussananon, 2003). These positive effects support the utility of edutainment for health promotion. Telenovelas - a type of television program that is very popular in Latin America, India, and Africa - are being used to encourage cancer screenings among adults (“Telenovelas Provide Platform," 2012) and could also be used to deliver messages regarding pubertal changes and safe menstrual hygiene practices. Because telenovelas are family programs, there is a potential to educate parents and youth at the same time, which could boost the impact of these messages. Edutainment is touted as a useful way to engage and educate students both in and out of the classroom (e.g., https://www.edsys.in/edutainment-beneficial-kids/); however, rigorous evaluations are needed to ensure that messages have the desired effects for youth.

Health care providers. A substantial number of U.S. adolescents turn to healthcare professionals for various kinds of health-related information. In a recent survey, nearly $70 \%$ of U.S. teenagers reported that they get "some" or "a lot" of health information from doctors and nurses (Wartella et al., 2016). It is unclear, however, how many receive information on puberty from medical professionals. Current pediatric guidelines recommend covering puberty at the annual well-visit beginning at 7-8 years of age, with genital examinations recommended during adolescence (Hagen, Shaw, \& Duncan, 2017; https://brightfutures.aap.org). Moreover, when young people get a well visit, they are more likely to receive a broader range of services including time alone with their clinician, which may include discussion of puberty and sexual development (Adams, Park, Tweitmeyer, Brindis, \& Irwin, in press). However, less than half (48\%) of adolescents (ages 10-17) currently receive a well visit, which is the most likely time for puberty to be discussed (National Adolescent and Young Health Information Center, 2017). Required sports physicals are another opportunity for adolescents to receive puberty information and often a genital exam (in boys), but these physicals are limited to youth who participate in organized sports.

Recent developments in health care policy in the U.S could increase adolescents' contact with health care providers and improve their quality of care. With full implementation of the Affordable Care Act (ACA), the annual well-visit for children and adolescents has no copayment, which has increased the number of youth who receive well-visits from $41 \%$ to $48 \%$ (Adams, Park, Tweitmeyer, Brindis, \& Irwin, 2018). Furthermore, training for pediatric residents in the U.S. must include at least one month in adolescent medicine (Accreditation 
Council for Graduate Medical Education, 2018), and there is a growing cohort of pediatricians and nurse practitioners who are interested in adolescents and more willing to address their concerns. However, there are still relatively few adolescent medicine doctors (less than 1,000 Board Certified Adolescent Medicine Specialists in the U.S.), and for youth without access to such doctors, health care on puberty-related topics may be limited (American Board of Pediatrics, 2018; Council of Pediatric Subspecialties, 2016; National Research Council and Institute of Medicine, 2009). Moreover, legislative efforts to dismantle the ACA could jeopardize the positive trend in well visits, with negative implications for adolescent health.

\section{Characteristics of Effective Puberty Programs}

Despite the dearth of evaluation data regarding puberty education programs, insights regarding effective health education can be gleaned from the broader literature on sexual education and positive youth development programs as well as recommendations from international organizations. To these insights, we add recent research findings on puberty and adolescence that could inform puberty programs.

\section{Insights from Interventions with Youth}

Sexual education programs. Because puberty education and sexual education overlap in content, evaluations of sexual education curricula are relevant for identifying the features of effective puberty education programs. Reviews of school-based sexual education programs in and outside the U.S. (Kirby \& Laris, 2009; Kirby et al., 2007; see also Santelli et al., 2017) have identified characteristics related to curriculum development, content, and implementation that are associated with more effective programs. Regarding program content, successful programs tend to set specific health goals (e.g., preventing STIs), provide clear messages about specific behaviors linked to those goals (e.g., using condoms), create a safe environment for discussion, and use multiple activities to address risk and protective factors for outcomes of interest. Moreover, programs with activities that are culturally and developmentally appropriate and that actively involve participants are more likely to be effective. Many of these program features have been endorsed in national guidelines for health education (Joint Committee on National Health Education Standards, 2007) and are relevant for puberty programs as well. However, because puberty is a biological process rather than a risky behavior such as unprotected sex, puberty programs can place less emphasis on behavior change techniques and peer resistance skills and more on helping youth understand pubertal changes and develop positive attitudes 
towards their bodies. Behavioral change approaches could still be used to promote healthy choices during puberty, such as choosing water instead of sugar-loaded drinks to avoid weight gain, acne, and poor sleep patterns.

Positive youth development programs. Because the effects of sexual education programs are often short-lived, many prevention scientists recommend positive youth development (PYD) programs to produce more lasting effects on youth behavior (Gavin, Catalano \& Marko, 2010; Leman, Smith, \& Petersen, 2017). PYD programs are designed to foster youths' general competencies and psychological resources while also creating support for positive youth development in families, schools, and communities. According to this model, nurturing positive development broadly by building skills and knowledge will lead to sustained healthy choices in multiple domains. Programs seek to promote social, cognitive, emotional, behavioral, and moral competencies as well as healthy bonding to others, prosocial norms, and psychological resources such as self-efficacy and positive identity (Catalano, Berglund, Ryan, Lonczak, \& Hawkins, 2004). Many of these competencies (e.g., self-efficacy, forging healthy relationships) could also support healthy practices and attitudes related to puberty. One option is to integrate puberty education into such programs to support long-term health and well-being.

Programs in the majority world. Based on a review of puberty programs in diverse majority world countries, a UNESCO report made recommendations for puberty education programs globally (Kettaneh et al., 2014). The report recommends that puberty education be integrated into primary school curricula in order to reach large numbers of youth before they leave school. It should begin in pre-adolescence (ages 5-8 years) and continue through ages 1518 years, with more complex concepts and skills being taught at older ages, building on those learned earlier. Program content should go beyond reproductive functions to promote an understanding of sexual desires experienced during puberty and the practical aspects of managing menstruation (for girls), and should seek to encourage respect, tolerance, and empathy between the sexes. Other recommendations are to incorporate alternative (non-didactic) teaching methods such as peer education, group problem solving activities, and dramatizations, particularly to address young people's values, attitudes, and skills.

In low-income countries, additional requirements for puberty programs include providing clean water, safe latrines, and privacy (for menstruating girls), as well as training teachers to be supportive, engaging the local community to support education efforts, and changing local social 
norms and attitudes regarding gender (Hennegan \& Montgomery, 2016; Kettaneh et al., 2014). This systemic approach is consistent with the positive youth development (PYD) model (Gavin et al., 2010) in which youth-focused interventions are connected to community supports and services (e.g., health clinics).

\section{Insights from Recent Research on Adolescence}

Along with insights from sexual education and positive youth development programs, research on puberty and adolescent development has implications for the design and delivery of puberty programs, particularly regarding their timing and content. In the following sections, we review key findings related to pubertal onset, other aspects of biological maturation, and individual differences and describe how they might be incorporated into puberty programs.

Pubertal onset, timing, and tempo. Puberty is occurring at younger ages than previously, with breast development in girls typically beginning at ages 8 or 9 and genital development in boys at ages 9 or 10, depending on race/ethnicity (Biro et al., 2013; HermanGiddens et al., 2012). There are also important individual differences in the timing and pace of pubertal development, and these variations are related to adolescents' behavior and emotions (e.g., Beltz, Corley, Bricker, Wadsworth, \& Berenbaum, 2014). Individual differences in pubertal timing and tempo mean that young adolescents of the same age or grade level will differ widely in their stage of pubertal development and may respond differently to interventions. As suggested by some evaluation studies (Cousineau et al. 2010; Rembeck \& Gunnarson, 2004), youth at different stages of pubertal development benefit from different content: pre-pubertal youth need enough information to feel prepared for pubertal changes to come, whereas youth in the midst of pubertal change may need more in-depth information and strategies for adapting to those changes. At the same time, younger children are less cognitively mature than older youth regardless of their pubertal status, limiting the kinds of information they can absorb. These competing needs complicate the process of providing developmentally appropriate pubertal education. A case can be made for organizing instruction by pubertal status; however, doing so could conflict with the desire to match instruction to cognitive maturity and would be challenging for schools, which typically organize instruction by grade level.

Neurobiological changes associated with puberty. Recent neurobiological research implicates puberty as a time of neural plasticity and reorganization affording new opportunities for learning as well as vulnerabilities that can contribute to negative outcomes (Galván 2010; 
Goddings et al., this section). Changes in the brain are related to increased reward seeking and novelty seeking which may lead to poor choices in situations that are affectively charged and involve potential rewards (Crone \& Dahl, 2012; Van Duijvenvoorde \& Crone, 2013). Peers activate the reward system in the brain, and adolescents are sensitive to how peers perceive them; as a result, youths take more risks when peers are present (Chein, Albert, O’Brien, Uckert, \& Steinberg, 2011). These alterations in brain function create psychological vulnerabilities that may contribute to health-compromising behaviors and increased emotionality. At the same time, the plasticity of the brain, in combination with social and cognitive changes, makes adolescence a time when patterns of thinking and behavior are forged that have important implications for future health and well-being, creating opportunities for intervention (Shlafer et al., 2014).

Changes in the Hypothalamic-Pituitary-Adrenal (HPA) system at puberty mean that adolescents are sensitive to stress, and there is evidence that their responses to stress during this time may reset their stress response systems (McCormick \& Mathews, 2007), affecting their vulnerability to depression and serious health problems in the future (Colich, Kircanski, FolandRoss, \& Gotlib, 2015; Dorn et al., this section). The physical, emotional, and social changes of puberty can be stressful, especially when they are not understood or when youth have insufficient coping skills. Thus, it is important to intervene during adolescence to reduce stress associated with puberty and to help youth learn healthy ways to manage stress.

Changes in the brain and HPA system at puberty underscore the importance of timely puberty education to reduce uncertainty and anxiety associated with pubertal changes. Discussing pubertal changes in emotionality and peer salience as part of puberty education would normalize these changes, potentially reducing their stressfulness for youth. Moreover, to ensure healthy choices, adolescents need tools to help them manage their emotions and choose wisely even when peers are present or emotions run "hot" (Suleiman \& Brindis, 2014); they also need strategies for managing stress.

Sexual minority youth. Research indicates that lesbian, gay, bisexual, transgender, and questioning (LGBTQ) have unique pubertal experiences (Deardorff et al., this issue). Youths with a same-sex or bisexual orientation may be distressed to find they are romantically or sexually attracted to same-sex individuals and may experience harassment or discrimination as a result of the associated stigma (Almeida, Johnson, Corliss, Molnar, \& Azrael, 2009; Huebner, Thoma, \& Neilands, 2015; Meyer, 2003). Furthermore, coming out risks rejection by family 
members and victimization by peers (Kosciw, Palmer, \& Kull, 2015). The challenges for transgender youths may be even greater, as their physical development is at odds with their gender identity. This can lead to emotional distress, including extreme discomfort with their bodies, at a time when they are also sorting out their sexual orientation (Ristori \& Steesma, 2016; Vance, Ehrensaft, \& Rosenthal, 2014). There has been a marked uptick in psychosocial interventions offered within medical settings to address issues related to pubertal development among transgender youth.

Traditional approaches to puberty education that focus on biological processes have been criticized for being insensitive to the needs of sexual minority youth. Placing too much emphasis on puberty as a biological process that results in reproductive capability curtails the opportunity to help students understand the non-reproductive aspects of their physical maturation and ignores the extent to which the meaning of puberty is culturally and socially defined. Furthermore, an emphasis on reproductive functions implies a heterosexual orientation, contrary to the experience of some youth (Diorio \& Munro, 2003). LGBTQ youth may benefit from a more inclusive approach to puberty and sexuality education and from online resources tailored to their developmental needs (Gowen \& Winges-Yanez, 2014). Despite the need, few LGBTQ youth experience inclusiveness in their health education: in a national survey, less than five percent of LGBT youth in grades 6-12 reported being exposed to positive representations of LGBT-related topics in their health classes (Kosciw, Greytak, Palmer, \& Boesen, 2014).

Racial and ethnic diversity. There is growing evidence that the meaning and experience of puberty is shaped by the sociocultural context and varies by race, ethnicity, and culture (see Deardorff et al, this issue). Projections that minority children will comprise over half of the U.S. child population by 2020 (Child Trends Data Bank, 2016) make consideration of ethnic/racial differences in experiences a timely issue for educational programs and policy. Racial differences in timing of puberty are well documented, and a small but growing body of work has begun to examine racial/ethnic differences in the experience of puberty (Deardorff et al., this issue). For example, there is some evidence that pubertal timing interacts with race to predict vulnerability to adjustment problems such as depression and substance use (Hamlat, Stange, Abramson, \& Alloy, 2014; Tanner-Smith, 2012). Insights for incorporating cultural diversity into puberty programs can be garnered from successful sexual education programs, which have drawn on strong cultural theory and empirical research to ensure that sexual 
education approaches and content are relevant, meaningful, and contextually salient for African American youth and their parents (Jemmott, Jemmott, \& Fong, 2010; Lawrence et al., 2017; see Johnson et al., 2009 for a review) and for Latino youth (Villarruel, Loveland, \& Ronis, 2010; Villarruel, Zhou, Gallegos, Ronis, 2010).

Special populations. Sexual education has been recommended for special needs populations, including youth with autism (Beddows \& Brooks, 2016; Curtiss \& Ebata, 2016), intellectual disabilities (Gougeon, 2009; McDaniels \& Fleming, 2016), and chronic illness (Bakke, 2016). These youth (and other special populations) would likely benefit from education on pubertal changes and hygiene practices that is tailored to their needs and capabilities.

Summary. Taken together, the insights from previous intervention studies and current research on adolescents suggest that, to be effective, puberty programs should have clear program goals, use developmentally appropriate and cultural relevant materials, employ nondidactic teaching strategies to engage youth, and involve multiple social contexts (e.g., parents and school) to support program goals. Based on recent research on adolescence, puberty education should start early, attend to individual variations in pubertal development, and include discussion of emotions, stress management, and peer influence. Additionally, the distinct experiences of LGBT youth and youth from diverse ethnic, racial, and cultural groups need to be included. Where feasible, it would be helpful to use teaching approaches that capitalize on the motivational aspects of pubertal brain changes, e.g., by incorporating rewards and peer activities.

\section{The Role of Policy}

Policies at the international, national and local level are necessary to support the provision of effective puberty education. International treaties mandate access to information and health as human rights (e.g., International Covenant on Civil and Political Rights, 1966). In particular, the International Covenant on Economic, Social and Cultural Rights (1966) protects "the right of everyone to the enjoyment of the highest attainable standard of physical and mental health," a right which the U.N. Committee on Economic, Social and Cultural Rights (2000) has interpreted as including "access to health-related education and information, including on sexual and reproductive health" (p. 130). States are charged with the responsibility to take actions to realize this right. Applying these standards to children, the U.N. Committee on the Rights of the Child (2003) has stated that access to adequate HIV/AIDS and sexual health information is critical to children's rights to health and information. Puberty education can be justified within 
this framework. The UNESCO report (Kettaneh et al., 2014) argues that puberty education is "an essential aspect of education to enable a healthy transition into adolescence and through to adulthood (p. 38)."

National and state policies. Most nations of the European Union mandate sex education (Baumont \& Maguire, 2013), which typically includes some information on puberty. In 2008, ministries of education and health throughout Latin American and the Caribbean adopted a joint declaration ("Preventing through Education," 2008) stating a commitment to comprehensive sex education. Moreover, in some majority world countries puberty/menstrual education has been incorporated into the official school curriculum approved by ministries of education (Kettaneh et al., 2014). Unlike these countries, the U.S. has no national health education policy that mandates specific content; instead, policy is set by the state and sometimes the local school district. The National Health Education Standards endorsed by the CDC outline the kinds of concepts and skills that should be taught in an effective health education program, but they are generic guidelines relevant to any health topic and do not identify specific content. Moreover, they are not legally binding. Currently, more than $75 \%$ of schools report that they follow national, state, or district health education standards (CDC, 2015).

In the U.S., some state laws and policies mandate instruction in human growth and development in conjunction with policies related to education on sexuality, HIV/STD prevention, or pregnancy prevention. The National Association of State Boards of Education has compiled a searchable database of state laws and policies related to health education (http://statepolicies.nasbe.org/). According to this database, approximately 10 states mention instruction in human development and/or growth in their policies. Even in these states, instruction is not always mandated, and, in virtually all cases, parents have the option to exempt their children from unwanted instruction.

Standards and guidelines on puberty education. In the absence of federal policy, several U.S. organizations have developed guidelines for sexual education that include puberty as a component. The Guidelines for Comprehensive Sexuality Education, published by SEICUS (Sexuality Information and Education Council of the United States) identify human development as a key component of sexual education, with puberty as a topic within that domain (National Guidelines Task Force, 2004). Building on this, the Future of Sex Education Initiative (2012) developed National Sexuality Education Standards for comprehensive sexual education, 
including mastery of age-graded content and skills related to "puberty and adolescent development" by grades 5, 8 , and 12 . International guidelines developed by the International Planned Parenthood Federation and UNESCO also include puberty content as a component of sexual education (Braeken, Shand, \& de Silva, 2006; International Technical Guidance, 2018).

\section{Recommendations for Research, Programs, and Policies}

The literature on puberty education in the U.S. and elsewhere, combined with insights from intervention studies and research on adolescent development, lead to several recommendations for advancing the scientific knowledge base and designing puberty education programs. Although extensive policy recommendations regarding puberty education would be premature at this point, we also offer some initial recommendations for policy in the U.S.

\section{Recommendations for Research}

- National surveys of puberty instruction. There is a critical need to determine what is being taught about puberty in the U.S. and elsewhere. A national survey of schools such as the SHPPS study is needed to collect specific data on puberty instruction. The survey would document which puberty topics are covered at each grade, as well as the degree of comprehensiveness, inclusiveness, and attention to diversity in the curriculum, and any information on program outcomes. A useful resource for such studies is a template for comprehensive sexuality education developed by the Future of Sex Education Initiative (http://www.futureofsexed.org/documents/josh-fose-standards-web.pdf). This template specifies core concepts to be mastered by specific grades and could be modified to survey schools about their puberty instruction.

- Surveys of youth. A complementary approach is to survey youth about their puberty education and knowledge. Research has identified deficiencies in both puberty content and instructional approach (e.g., Koch, Robbins, Porter \& Gyorke, 2009), and surveys suggest that some youth, especially boys, do not receive puberty education prior to puberty (Omar, McElderry, \& Zakharia, 2003). A recent review of qualitative studies of puberty experiences among low-income girls in the U.S. revealed a lack of preparation for puberty and negative experiences related to menarche and menstruation, suggesting that deficiencies in puberty education persist for many girls as well (Herbert et al., 2017). Research is needed to determine gaps in puberty education in the population as a whole. 
- Program evaluation. Because puberty education is rarely evaluated separately from general sexual education, its efficacy is largely unknown. Evaluations of puberty education provided in free-standing interventions (e.g., menstrual hygiene programs) have shown promising program effects on knowledge and attitudes, but evaluations of classroom-based puberty education are rare. There is a critical need for puberty education programs of all types to be rigorously evaluated and the findings published in scientific journals. Where puberty content is embedded in broader sexual or health education curricula, the puberty component must be evaluated separately. Programs for boys must be evaluated as well as programs for girls, and, if programs are intended to educate both girl and boys, gender differences in program effects should be examined. Similarly, universal curricula that are intended to be inclusive of LGBTQ youth need to be evaluated across youth with distinct sexual identities to determine whether they are sufficiently relevant and inclusive.

- Dissemination of evidence-based programs. Once programs have shown clear evidence of effectiveness, they should be disseminated widely to researchers and educators. Most helpful would be an archive of evidence-based programs for schools, communities, and clinics to choose from, along with manuals and templates to facilitate reproducibility. This could be done through a central website such as that created by the Office of Adolescent Health for teen pregnancy prevention programs. The database is searchable, allowing educators to identify curricula that are well suited to the needs of their students and local contexts.

- Internet and other media. Online programs and phone apps are promising ways to provide supplemental content on puberty in the classroom and at home. They can also be used to deliver educational interventions and to assess outcomes of puberty programs designed to improve knowledge, attitudes, or hygiene. There is evidence that internetbased interventions can be used to deliver educational interventions to pediatricians and to enhance body image among pubertal youth. Other programs and apps are available, but finding high-quality ones is challenging and most are in need of evaluation. Research is also needed on how youths and parents navigate puberty websites and what information is accessed. Collaboration with the field of information science, particularly with social-behavioral researchers within this field, is needed to improve the reach and 
potency of web offerings and to understand the use of computer-mediated environments for puberty education. The utility of edutainment as a strategy for improving puberty knowledge, attitudes, and practices needs to be explored and rigorously evaluated.

- Diverse experiences of puberty. To improve puberty education programs, further research is needed on the pubertal experiences of adolescents from diverse racial/ethnic backgrounds and their implications for health. The recent review of qualitative research on puberty experiences in low-income girls (Herbert et al., 2017) is an important start, but quantitative studies with representative samples are needed to confirm the findings and extend them to boys and to racial/ethnic minority youth from higher income families.

- Sexual minority and transgender youth. More research is needed on the responses of LGBTQ youth to puberty education programs and how programs could be improved to better suit their needs. Transgender youth may benefit from supplementary programs or services (e.g., counseling) designed to help them deal with their changing bodies. More research on these youth and options for supporting them is needed.

- Youth with special needs. The need for puberty education programs designed for youth with special needs/disabilities should be assessed.

\section{Recommendations for Puberty Education}

- Program timing and organization. Puberty programs should start early enough to ensure that most youth receive timely information about their changing bodies. We recommend that puberty education begin by $4^{\text {th }}$ grade (age 9 ) at the latest, in order to accommodate a majority of U.S. youth early in the pubertal process; starting even earlier (e.g., ages 6-8) would allow better preparation for the changes to come. Early maturing youth may need special programs to educate them at younger ages. Pubertal (or menarcheal) status should be considered in interventions that target young adolescents. Although it might be helpful to organize puberty education by pubertal stage rather than age, a more feasible alternative for schools would be to follow a grade-based puberty curriculum in which foundational concepts are taught early in primary school, followed by more complex information at later ages (e.g., Future of Sex Education, 2012).

\section{- Comprehensive curricula that normalize puberty as a common experience and} address individual differences in pubertal development. To understand and cope effectively with their experiences, adolescents need information on the emotional, 
psychological, and social changes of puberty as well as on physical and physiological changes. They also need to be educated regarding normal variations in the timing and tempo of puberty. Emphasizing that pubertal changes, and individual variations in these changes, are normal should reduce stress and anxiety about puberty. Promoting a healthy body image through positive messages is also important. In addition, adolescents need to learn strategies and skills for managing pubertal changes and their feelings about them, including how to handle their emotionality and vulnerability to risky behaviors and how to cope effectively with stress.

- Inclusive curricula. To address the need and experiences of LGBTQ youth programs should acknowledge variations in sexual orientation and gender identity, provide positive representations of LGBT youth, and promote acceptance of diverse orientations and experiences. The National Sexuality Education Standards (Future of Sex Education Initiative, 2012), which include "identity" as a core concept of sexuality education, could guide the development of inclusive puberty curricula.

\section{- Sensitivity to cultural and ethnic differences in puberty experience. Puberty} programs should be flexible enough to accommodate differences in experience among diverse youth. Schools with homogeneous populations can modify programs to increase their cultural and personal relevance for students; where the student body is diverse, the experiences of youth from different racial, ethnic, and cultural backgrounds can be explored through peer discussions to illuminate divergent experiences and foster critical analysis of the underlying social and contextual forces.

- Attention to the social implications of pubertal development. Many pubertal youth are subjected to unwanted sexual attention, teasing, and harassment. In some cultures, pubertal girls are viewed as potential sexual or marriage partners, regardless of their readiness for such relationships (Kettaneh et al., 2014). Programs should acknowledge these reactions and teach effective strategies for coping with them. Encouraging empathy and respect between the sexes may reduce teasing and harassment. In some settings, community leaders will need to be engaged to address gender norms and attitudes in the broader community.

- Health care providers. Training of future health care providers needs to be expanded to incorporate up to date information on adolescence and pubertal development. This will 
allow greater attention to pubertal development and associated health care during the annual well-visit for children and adolescents consistent with current pediatric guidelines. Currently, there is a major focus on the health of adolescents throughout the world, with the development of guidelines for educating and training those professionals caring for young people. This creates an opportunity for undergraduate, graduate and post-graduate training programs to provide a firm understanding of the physiological and psychosocial changes and health conditions associated with adolescence (Kokotailo, Baltag, \& Sawyer, 2018). Attention to puberty during middle childhood and adolescence would provide the framework for expanding the content in these curricula (Shlafer et al., 2014).

\section{Recommendations for U. S. Policy}

- A thorough review of education policies in the U.S. is needed. The goal would be to determine whether states mandate puberty education and if the information provided is required to be medically accurate, developmentally appropriate, and inclusive of diversity. A review of policies at the school level would also be useful, as many states leave content decisions to the school district. Such as review might also clarify the extent to which required puberty education differs for boys and girls.

- To develop and assess puberty education curricula, schools can draw on guidance from SEICUS (National Guidelines Taskforce, 2004), the Future of Sex Education Initiative (2012), and UNESCO (International Technical Guidance, 2018). A template for comprehensive sexuality education developed by the Future of Sex Education Initiative (2012) specifies core concepts and skills related to puberty to be mastered at various grade levels (www.futureofsexeducation.org). Following implementation, high quality empirical evaluation should be conducted so that efficacy of programs can be determined.

- Educational policies should be guided by evidence-based research and, where feasible, should incorporate the principles of effective programs for youth and research on adolescent development. States should commit to requiring that the information delivered in school-based health education (including puberty education) is evidencebased, medically accurate, and nondiscriminatory. Following implementation, high quality empirical evaluation should be conducted to assess program efficacy.

- From a U.S. policy perspective, the linkage of puberty education to sexual education creates barriers to improving puberty education, both because puberty education is not 
evaluated separately within sexual education programs and because sexual education remains controversial among policymakers. For these reasons, it would be helpful to decouple puberty education from sexual education in educational policy and practice.

- The increasing availability of information on the internet requires attention because there is currently little government regulation of online content. Therefore, private gatekeepers are needed, for example, to provide useful phone aps that offer safe, scientifically-based information for youth. Scientific societies could work in partnership with parent groups and health professionals or medical associations. More broadly, regulations are needed to ensure the validity of information gleaned from the screen.

\section{Conclusions}

Puberty programs and policies are an important way to support healthy development among youth around the world. There is a need for such policies and programs globally, with local adjustments to make them culturally relevant, inclusive, and effective for the particular youth population to be served. A major impediment to this work is the lack of rigorous evaluation and comparison (or even cataloguing) of existing puberty programs. More consistent and rigorous evaluation is needed, along with systematic reviews comparing programs that have been evaluated. Although most puberty education will continue to be provided in schools, puberty programs are also offered in other community settings; in either case, buy-in from various stakeholders (e.g., school, family, health care providers, government or community leaders) will facilitate sustainability and improve program effectiveness. While much is known about the kinds of educational strategies that are appealing to youth, we believe that attention to new research on puberty and adolescence will provide additional insights that allow program providers (and policymakers) to improve puberty programs. In turn, providing young people with the knowledge and understanding they need to cope with pubertal changes and teaching them skills that support healthy behaviors and positive attitudes towards their bodies will improve their mental and physical well-being during adolescence and potentially prevent related health problems in adulthood. Globally, policies that support effective puberty education and health practices for youth can contribute to a healthier population and higher educational attainment, improving productivity and reducing the burden of illness in society as a whole.

\section{References}


Accreditation Council for Graduate Medical Education (2017). ACGME program requirements for graduate medical education in pediatrics. Retrieved April 26, 2018 from http://www.acgme.org/Portals/0/PFAssets/ProgramRequirements/320_pediatrics_201707-01.pdf?ver=2017-06-30-083432-507

Adams, S. H., Park, M. J., Twietmeyer L., Brindis, C. D., \& Irwin, C. E. (in press). Increasing delivery of preventive services to adolescents and young adults: Does the preventive visit help? Journal of Adolescent Health. https://doi.org/10.1016/j.jadohealth.2018.03.013

Adams, S. H., Park, M. J., Twietmeyer, L., Brindis, C. D., Irwin, C. E. (2018). Association between adolescent preventive care and the role of the Affordable Care Act. JAMA Pediatrics, 172, 43-48. doi: 10.1001/jamapediatrics.2017.3140

Almeida, J., Johnson, R. M., Corliss, H. L., Molnar, B. E. \& Azrael, D. (2009). Emotional distress among LGBT youth: The influence of perceived discrimination based on sexual orientation. Journal of Youth and Adolescence, 38, 1001-1014. http://0dx.doi.org.library.unl.edu/10.1007/s10964-009-9397-9

American Board of Pediatrics. Verification of subspecialty status in Adolescent Medicine. Retrieved April 25, 2018 from https://www.abp.org/

Afsari, A., Mirghafourv, M., Valizadeh, S., Abbasnezhadeh, M., Galshi, M., \& Fatahi, S. (2017). The effects of educating mothers and girls on the girls' attitudes toward puberty health: A randomized controlled trial. International Journal of Adolescent Medicine and Health, 29. doi: 10-15-15/ijamh-2015-0043

Bakke, A. (2016). Empowering our youth: Initiating sexual health education on the inpatient unit for the chronically ill pediatric patient. Urologic Nursing, 36, 267-273. doi:10.7257/1053-816X.2016.36.6.267

Banerjee, A., La Ferrara, E., \& Orozco, V. (2018). "The entertaining way to behavioural change: Fighting HIV with MTV in Nigeria.” Retrieved from https://voxdev.org/topic/healtheducation/entertaining-way-behavioural-change-fighting-hiv-mtv-nigeria

Baumont, K., \& Maquire, M. (2013). Policies for Sexuality Education in the European Union. European Parliament, Directorate General for Internal Policies, Policy Department C: Citizens' Rights and Constitutional Affairs. Retrieved from http://www.europarl.europa.eu/studies 
Beddows, N., Brooks, R. (2016). Inappropriate sexual behaviour in adolescents with autism spectrum disorder: What education is recommended and why. Early Intervention in Psychiatry, 10, 282-289. doi: 10.1111/eip.12265.

Beltz, A. M., Corley, R. P., Bricker, J. B., Wadsworth, S. J., \& Berenbaum, S. A. (2014). Modeling pubertal timing and tempo and examining links to behavior problems. Developmental Psychology, 50, 2715-2726. doi:10.1037/a0038096

Biro, F. M., Greenspan, L. C., Galvez, M. P., Pinney, S. M., Teitelbaum, S., Windham, G. C.,...Wolff, M. S. (2013). Onset of breast development in a longitudinal cohort. Pediatrics, 132, 1019-1027. doi:10.1542/peds.2012-3773

Braeken, D., Shand, T., \& de Silva, U. (2006, updated 2010). IPPF framework for comprehensive sexual education (CES). Retrieved from http://Www.ippf.org/sites/default/files/ippf_framework_for_comprehensive_sexuality_ed ucation.pdf

Catalano, R. F., Berglund, M. L., Ryan, J. A., Lonczak, H. S., \& Hawkins, J. D. (2004). Positive youth development in the United States: Research findings on evaluations of positive youth development programs. Annals of the American Academy of Political and Social Science, 591, 98-124.

Centers for Disease Control and Prevention. (2015). Results from the School Health Policies and Practices Study 2014. Retrieved from: https://www.cdc.gov/healthyyouth/data/shpps/pdf/shpps-508-final_101315.pdf Chandra-Mouli, V., \& Patel, S.V. (2017). Mapping the knowledge and understanding of menarche, menstrual hygiene and menstrual health among adolescent girls in low- and middle-income countries. Reproductive Health, 14, 30. doi: 10.1186/s12978-017-0293-6 Chein, J., Albert, D., O’Brien, L., Uckert, K., \& Steinberg, L. (2011). Peers increase adolescent risk taking by enhancing activity in the brain's reward circuitry. Developmental Science, 14, 22, F1-F10. doi: 10.1111/j.1467-7687.2010.01035.x

Child Trends Data Bank (2016). Racial and Ethnic Composition of the Child Population. Retrieved from: https://www.childtrends.org/wp-content/uploads/2016/07/60_RacialComposition.pdf 
Colich, N. L., Kircanski, K., Foland-Ross, L. C., Gotlib, I. H. (2015). HPA-axis reactivity interacts with stage of pubertal development to predict the onset of depression. Psychoneuroendocrinology, 55, 94-101.

Council of Pediatric Subspecialties-Adolescent Medicine. (2016). Retrieved April 25, 2018 from www.pedsubs.org/SubDes/AdolescentMedicine.cfm

Cousineau, T. M., Franko, D. L., Trant, M., Rancourt, D., Ainscough, J., Chaudhuri, A., \& Brevard, J. (2010). Teaching adolescents about changing bodies: Randomized controlled trial of an Internet puberty education and body dissatisfaction prevention program. Body Image 7, 296-300.

Crone, E. A, \& Dahl, R. E. (2012). Understanding adolescence as a period of social-affective engagement and goal flexibility. Nature Reviews Neuroscience, 13, 636-650. doi: $10.1038 /$ nrn3313.

Curtiss, S. L., \& Ebata, A. T. (2016). Building capacity to deliver sex education to individuals with autism. Sexuality and Disability, 34, 27-47. doi: 10.1007/s11195-016-9429-9

Das, P., Baker, K. K., Dutta, A, Swain, T., Sahoo, S., Das, B., S.,...Torondel, B. (2015). Menstrual hygiene practices, WASH access and the risk of urogenital infection in women from Odisha, India. PLOS ONE, 10. https://doi.org/10.1371/journal.pone.0130777

DellaVigna, S., \& La Ferrara, E. (2015). Economic and social impacts of the media. In S. Anderson, D. Strömberg, \& J. Waldfogel (Eds.), Handbook of media economics, Vol. 1 (pp. 723-768). Amsterdam: North-Holland.

DiClemente, R. J., Salazar, L. F., \& Crosby, R. A. (2007). A review of STD/HIV preventive interventions for adolescents: Sustaining effects using an ecological approach. Journal of Pediatric Psychology, 32, 888-906. https://doi.org/10.1093/jpepsy/jsm056

Diorio, J. A., \& Munro, J. (2003). What does puberty mean to adolescents? Teaching and learning about bodily development. Sex Education, 3, 119-131. doi: $10.1080 / 1468181032000092410$

Ens, A., Janzen, K., \& Palmert, M. R. (2017). Development of an online learning module to improve pediatric residents' confidence and knowledge of the pubertal examination. Journal of Adolescent Health, 60, 292-298. http://dx.doi.org/10.1016/j.jadohealth.2016.10.006 
Fakhri, M., Hamzehgardeshi, Z., Golchin, N. A. H., \& Komili, A. (2012). Promoting menstrual health among Persian adolescent girls from low socioeconomic backgrounds: A quasiexperimental study. BMC Public Health, 12, 193. http://www.biomedcentral.com/1471$2458 / 12 / 193$

Future of Sex Education Initiative (2012). National Sexuality Education Standards: Core content and skills, K-12. Future of Sex Education Initiative. (2012). http://www.futureofsexed.org/documents/josh-fose-standards-web.pdf

Galván, A. (2010). Neural plasticity of development and learning. Human Brain Mapping, 31, $879-890$.

Gavin, L. E., Catalano, R. F., \& Markham, C. M. (2010). Positive youth development as a strategy to promote adolescent sexual and reproductive health. Journal of Adolescent Health, 46, S1-S6. doi: http://dx.doi.org/10.1016/j.jadohealth.2009.12.017

Gougeon, N., A. (2009). Sexuality education for students with intellectual disabilities, a critical pedagogical approach: outing the ignored curriculum. Sex Education, 9, 277-291.

Gowen, L. K., \&Winges-Yanez, N. (2014). Lesbian, gay, bisexual, transgender, queer, and questioning youths' perspectives of inclusive school-based sexuality education. Journal of Sex Research, 51, 788-800. http://dx.doi.org/10.1080/00224499.2013.806648

Greenspan,L., \& Deardorff, J. (2014). The new puberty: How to navigate early development in today's girls. New York, NY: Rodale.

Guttmacher Institute. (2018). Sex and HIV education. https://www.guttmacher.org/statepolicy/explore/sex-and-hiveducation?gclid=EAIaIQobChMIl_jfnNSX2wIVFksNCh2BFg56EAMYAiAAEgLAZfD BWE

Hagen, J. F., Shaw, J. S., \& Duncan, P. M. (2017). Bright Futures Guidelines for Health Supervision of Infants, Children, and Adolescents (4th ed). Elk Grove Village, IL: American Academy of Pediatrics.

Hamlat, E. J., Stange, J. P., Abramson, L, Y., Alloy, L. B. (2014). Early pubertal timing as a vulnerability to depression symptoms: Differential effects of race and sex. Journal of Abnormal Child Psychology, 42, 527-538. doi: 10.1007/s10802-013-9798-9 
Hennegan, J., Dolan, C., Steinfield, L., \& Montgomery, P. (2017). A qualitative understanding of the effects of reusable sanitary pads and puberty education: implications for future research and practice. Reproductive Health, 14, 78. doi: 10.1186/s12978-017-0339-9.

Hennegan, J., \& Montgomery, P. (2016). Do menstrual hygiene management interventions improve education and psychosocial outcomes for women and girls in low and middle income countries? A systematic review. PLoS ONE, 11(2): e0146985.

doi:10.1371/journal.pone.0146985

Herbert, A. C., Ramirez, A. M., Lee, G., North, S. J., Askari, M. S., West, R. L., \& Sommer, M. (2017). Puberty experiences of low-income girls in the United States: A systematic review of qualitative literature from 2000 to 2014. Journal of Adolescent Health, 60, 363-379. https://doi.org/10.1016/j.jadohealth.2016.10.008

Herman-Giddens, M.E., Slora, E. J., Wasserman, R. C., Bourdony, C.J., Bhapkar, M. V., Koch G. G., \& Hasemeier, C. M. (1997). Secondary sexual characteristics and menses in young girls seen in office practice: A study from the Pediatric Research in Office Settings network. Pediatrics, 99, 505-12.

Herman-Giddens, M. E., Steffes, J., Harris, D., Slora, E., Hussey, M., Dowshen, S. A.,...Reiter, E. O. (2012). Secondary sexual characteristics in boys: Data from the Pediatric Research in Office Settings Network. Pediatrics, 130, e1058-e1068. doi:10.1542/peds.2011-3291

Huebner, D. M., Thoma, B. C., Neilands, T. B. (2015). School victimization and substance use among lesbian, gay, bisexual, and transgender adolescents. Prevention Science, 16, 734743. http://0-dx.doi.org.library.unl.edu/10.1007/s11121-014-0507-x

International Covenant on Civil and Political Rights. (Dec. 16, 1966). U.N.T.S, 999, 171.

Retrieved from: http://www.ohchr.org/EN/ProfessionalInterest/Pages/CCPR.aspx International Covenant on Economic, Social and Cultural Rights. (Dec. 16, 1966). U.N.T.S, 993, 3. Retrieved from: http://www.ohchr.org/EN/ProfessionalInterest/Pages/CESCR.aspx

International Technical Guidance on Sexuality Education: An evidence-informed approach (revised ed.). (2018). United Nations Educational, Scientific and Cultural Organization. Retrieved from http://www.unaids.org/sites/default/files/media_asset/ITGSE_en.pdf

Jemmott J. B., Jemmott, L.S., Fong, G. T. (2010). Efficacy of a theory-based abstinence-only intervention over 24 months: A randomized controlled trial with young adolescents. 
Archives of Pediatric Adolescent Medicine, 164, 152-159.

doi:10.1001/archpediatrics.2009.267

Johnson, B. T., Scott-Sheldon, L., Smoak, N. D., LaCroix, J. M., Anderson, J. R., \& Carey, M. P. (2009). Behavioral interventions for African-Americans to reduce sexual risk of HIV: A meta-analysis of randomized controlled trials. Journal of Acquired Immune Deficiency Syndrome, 51, 492-501. doi: 10.1097/QAI.0b013e3181a28121

Joint Committee on National Health Education Standards. National Health Education Standards, Second Edition, Achieving Excellence. Atlanta, GA: American Cancer Society, 2007. Retrieved from: http://www.cdc.gov/healthyyouth/sher/standards

Kettaneh, A., Pulizzi, S., \& Todesco, M. (2014). Puberty education and menstrual hygiene management. Good policy and practice in health education, Booklet 9. Paris, France: United Nations Educational, Scientific and Cultural Organization. Retrieved from http://unesdoc.unesco.org/images/0022/002267/226792e.pdf

Kirby, D., \& Laris, B. A. (2009). Effective curriculum-based sex and STD/HIV education programs for adolescents. Child Development Perspectives, 3, 21-29.

Kirby, D., Laris, B. A., \& Rolleri, L. A. (2007). Sex and HIV education programs: Their impact on sexual behaviors of young people throughout the world. Journal of Adolescent Health 40,206-217. doi:10.1016/j.jadohealth.2006.11.143.

Koch, P. B., Robbins, S. C., Porter, A., \& Gyorke, A. (2009). What about puberty? A overlooked part of comprehensive education. In Schroeder, E. \& Kuriansky, J. (Eds.), Sexuality education: Past, present, and future (Vol 3.) Principles and practices (pp. 40-61). Westport, CN: Praeger.

Kokotailo, P. K., Baltag, V., \& Sawyer, S. M. (2018). Educating and training the future adolescent health workforce. Journal of Adolescent Health, 62, 511-524. doi: 10.1016/j.jadohealth.2017.11.299.

Kosciw, J., G., Palmer, N. A., \& Kull, R. M. (2015). Reflecting resiliency: openness about sexual orientation and/or gender identity and its relationship to well-being and educational outcomes for LGBT students. American Journal of Community Psychology, 55, 167-78. doi: 10.1007/s10464-014-9642-6.

Kosciw, J. G., Greytak, E. S., Palmer, N. A., Boesen, M. J. (2013). The 2013 National 
School Climate Survey: The experiences of lesbian, gay, bisexual and transgender youth in our nation's schools. Retrieved from:

https://www.glsen.org/sites/default/files/2013\%20National\%20School\%20Climate\%20S urvey\%20Full\%20Report_0.pdf

Kuhlmann, A. S., Henry, K., \& Wall, L. L. (2017). Menstrual hygiene management in resourcepoor countries. Obstetrics and Gynecological Survey, 72, 356-376. doi:

10.1097/OGX.0000000000000443.

Landry, D. J., Singh, S., \& Darroch, J. E. (2000). Sexuality education in fifth and sixth grades in U.S. Public Schools, 1999. Family Planning Perspectives, 32, 212-219. doi: https://doi.org/10.1363/3221200, https:/www.guttmacher.org/sites/default/files/pdfs/pubs/journals/3221200.pdf

Lahme, A. M., Stern, R., \& Cooper, D. (2016). Factors impacting on menstrual hygiene and their implications for health promotion. Global Health Promotion. https://doi.org/10.1177/1757975916648301

Lawrence, T. Z., Akintobi, T. H., Miller, A., Archie-Booker, E., Johnson, T., \& Evans. D. (2017). Assessment of a culturally-tailored sexual health education program for African American youth. International Journal of Environmental Research and Public Health, 14. doi: 10.3390/ijerph14010014

Leman, P. J., Smith, E. P., Petersen, A. C., \& SRCD Ethnic-Racial Issues and International Committees (2017). Child Development, 88, 1039-1044.

http://dx.doi.org/10.1111/cdev.12860

Lupton, D. (2016). The use and value of digital media for information about pregnancy and early motherhood: a focus group study. BMC Pregnancy and Childbirth, 16, 171. doi: 10.1186/s12884-016-0971-3

Mason, L., Nyothach, E., Alexander, K., Odhiambo, F. O., Eleveld, A., Vulule, J....PhillipsHoward, P. A. (2013). 'We keep it secret so no one should know' - a qualitative study to explore young schoolgirls attitudes and experiences with menstruation in rural Western Kenya. PLoS ONE, 8, e79132.

McCartney, P. (2016). Nursing practice with menstrual and fertility mobile apps. American Journal of Maternal Child Nursing, 41, 61. doi: 10.1097/NMC.0000000000000202 
McCormick, C. M., \& Mathews, I. Z. (2007). HPA function in adolescence: role of sex hormones in its regulation and the enduring consequences of exposure to stressors. Pharmacology Biochemistry and Behavior, 86, 220-233.

McDaniels, B., \& Fleming, A. (2016). Sexuality education and intellectual disability: Time to address the challenge. Sexuality and Disability, 34, 215-225. doi: $10.1007 / \mathrm{s} 11195-016-9427-\mathrm{y}$

Meyer, I. H. (2003). Prejudice, social stress, and mental health in lesbian, gay and bisexual populations: Conceptual issues and research evidence. Psychological Bulletin, 129, 674697. doi:10.1037/0033-2909.129.5.674

Montgomery, P., Hennegan, J., Dolan, C., Wu, M., Steinfield, L., Scott, L. (2016). Menstruation and the cycle of poverty: A cluster quasi-randomised control trial of sanitary pad and puberty education provision in Uganda. PLoS ONE. doi:10.1371/journal.pone.0166122

National Adolescent and Young Health Information Center, University of San Francisco. Medical Expenditures Panel Survey [private data run] 2017. Agency for Healthcare Research Quality, U.S. Dept. of Health \& Human Services. Available at: https://meps.ahrq.gov/mepsweb/

National Guidelines Task Force. (2004). Guidelines for Comprehensive Sexuality Education: Kindergarten-12th Grade (3rd ed.). Sexuality Information and Education Council of the United States. Retrieved from http://www.siecus.org/_data/global/images/guidelines.pdf National Research Council and Institute of Medicine. (2009). Adolescent health services: Missing opportunities. Washington, DC: National Academies Press. https://doi.org/10.17226/12063

Natterson, C., \& Masse, J. (2013). The care and keeping of you 2: The body book for older girls. American Girl Publishing.

Office of Adolescent Health (2017). About the Teen Pregnancy Prevention (TPP) Program. https://www.hhs.gov/ash/oah/grant-programs/teen-pregnancy-prevention-programtpp/about/index.html

Omar, H., McElderry, D. M., \& Zakharia, R. (2003). Educating adolescents about puberty: What are we missing? International Journal of Adolescent Medicine and Health, 15, 79-83.

Parker, R., Wellings, K., \& Lazarus, J. V. (2009). Sexuality education in Europe: An overview of current policies. Sex Education, 9, 227-242. doi: 10.1080/14681810903059060 
Peltzer, K., \& Promtussananon, S. (2003). Evaluation of Soul City school and mass media life skills education among junior secondary school learners in South Africa. Social Behavior and Personality, 31, 825-834. doi: 10.2224/sbp.2003.31.8.825

Pew Research Center (March, 2013). Teens and technology 2013. Retrieved from http://www.pewinternet.org/2013/03/13/teens-and-technology-2013/

Pew Research Center. (May, 2018). Teens, social media \& technology 2018. Retrieved from http://www.pewinternet.org/2018/05/31/teens-social-media-technology-2018/

Pew Research Center (March, 2015). Communications technology in emerging and developing nations. Retrieved from http://www.pewglobal.org/2015/03/19/1-communicationstechnology-in-emerging-and-developing-nations/

Pew Research Center (Feb., 2016). Smartphone ownership and internet usage continues to climb in emerging economies. Retrieved from http://www.pewglobal.org/2016/02/22/smartphone-ownership-and-internet-usagecontinues-to-climb-in-emerging-economies/

Phillips-Howard P. A., Nyothach E., Ter Kuile, F. O., Omoto, J., Wang, D., Zeh, C...Laserson, K. F. (2016). Menstrual cups and sanitary pads to reduce school attrition, and sexually transmitted and reproductive tract infections: A cluster randomised controlled feasibility study in rural Western Kenya. BMJ Open, 6, e013229. doi: 10.1136/bmjopen-2016013229.

Planned Parenthood Federation (2017). 2016-2017 annual report of the Planned Parenthood Federation. Retrieved from https://www.plannedparenthood.org/uploads/filer_public/d4/50/d450c016-a6a9-4455bf7f-711067db5ff7/20171229_ar16-17_p01_lowres.pdf

Preventing through Education (2008). Ministerial Declaration, 1st Meeting of Ministers of Health and Education to Stop HIV and STIs in Latin America and the Caribbean. Retrieved from http://data.unaids.org/pub/basedocument/2008/20080801_minsterdeclaration_en.pdf Population Council (2012). Sexuality Education: A ten-country review of school curricula in East and Southern Africa. Paris, France: United Nations Educational, Scientific and Cultural Organization (UNESCO). Retrieved from: http://unesdoc.unesco.org/images/0022/002211/221121E.pdf 
Rani, M., Sheoran, P, Kumar, Y., \& Singh, N. (201 6). Evaluating the effectiveness of pubertal preparedness program in terms of knowledge and attitude regarding pubertal changes among pre-adolescent girls. Journal of Family and Reproductive Health, 10, 122-128. PMC5241356 http://jfrh.tums.ac.ir

Rembeck, G. I., \& Gunnarsson, R. K. (2004). Improving pre- and postmenarcheal 12-year-old girls' attitudes toward menstruation. Health Care for Women International, 25, 680-698. doi: 10.1080/07399330490458033

Ristori, J., \& Steensma, T. D. (2016). Gender dysphoria in childhood. International Review of Psychiatry, 28, 13-20. doi: 10.3109/09540261.2015.1115754

Ross, D. S., Dick, B., \& Ferguson, J. (Eds.) (2006). Preventing HIV/AIDS in young people: A systematic review of the evidence from developing countries. UNAIDS Inter-agency Task Team on Young People, World Health Organization.

Santelli, J. S., Kantor, L. M., Grilo, S. A., Speizer, I. S., Lindberg, L. D., Heitel, J.,...Ott, M. A. (2017). Abstinence-only-until-marriage: An updated review of U.S. policies and programs and their impact. Journal of Adolescent Health 61, 273-280.

Shah, S. P., Nair, R., Shah, P. P., Modi, D. K., Desai, S. A., \& Desai, L. (2013). Improving quality of life with new menstrual hygiene practices among adolescent tribal girls in rural Gujarat, India. Reproductive Health Matters, 21, 205-213. Doi: http://dx.doi.org/10.1016/S0968-8080(13)41691-9

Sheoran, B., Braun, R. A., Gaarde, J. P., \& Levine, D. K. (2014). The hookup: Collaborative evaluation of a youth sexual health program using text messaging technology. JMIR mHealth and uHealth, 2(4), e51. doi: 10.2196/mhealth.3583

Shlafer, R., Hergenroeder, A. C., Emans, S. J., Rickert, V. I., Adger, H., Spear, B... Resnick MD. (2014). Adolescence as a critical stage in the MCH Life Course Model. Maternal and Child Health Journal, 18, 462-466. doi:10.1007/s10995-013-1243-8.

Sommer, M. (2010). Where the education system and women's bodies collide: The social and health impact of girls' experiences of menstruation and schooling in Tanzania. Journal of Adolescence, 33, 521-529.

Sommer, M. (2011). An early window of opportunity for promoting girls' health: Policy implications of the Girl's Puberty Book Project in Tanzania. International Electronic Journal of Health Education, 14, 77-92. 
Sommer, M., \& Sahin, M. (2013). Overcoming the taboo: Advancing the global agenda for menstrual hygiene management for schoolgirls, American Journal of Public Health 103, 1556-1559. doi:10.2105/AJPH.2013.301374

Suleiman, A. B., \& Brindis, C. D. (2014). Adolescent school-based sex education: Using developmental neuroscience to guide new directions for policy and practice. Sexuality Research and Social Policy, 11, 1-16. doi:10.1007/s13178-014-0147-8

Sumpter, C., Torondel, B. (2013). A systematic review of the health and social effects of menstrual hygiene management. PLOS ONE, 8, e62004.

Tanner-Smith, E. E. (2012). Pubertal development and adolescent girls' substance use: Race, ethnicity, and neighborhood contexts of vulnerability. Journal of Early Adolescence, 32, 621-649

Telenovelas Provide Platform for Public Health Messages. (2012, January 25). Retrieved from https://www.pbs.org/newshour/health/encrucijadas-public-health-and-telenovelas-at-acrossroads

Tondare, D., Chandra, K., \& Kembhavi, R. S. (2011). Perception of adolescent boys regarding pubertal changes (physical, emotional and psychological) from urban slum area of Mumbai. Indian Journal of Public Health Research \& Development, 2, 42-46.

U.N. Committee on Economic, Social and Cultural Rights (2000). General Comment No. 14: The Right to the Highest Attainable Standard of Health. (pp. 128-48). Retrieved from: http://www.un.org/documents/ecosoc/docs/2001/e2001-22.pdf

U.N. Committee on the Rights of the Child (2003). General Comment No. 3: HIV/AIDS and the rights of the Child (para 13). Retrieved from https://www.unicef.org/aids/files/UNHCHR_HIV_and_childrens_rights_2003.pdf

Van Duijvenvoorde, A. C., \& Crone, E. A. (2013). The teenage brain: A neuroeconomic approach to adolescent decision making. Current Directions in Psychological Science, 22, 108-113.

Vance, S. R., Ehrensaft, D., \& Rosenthal, S. M. (2014). Psychological and medical care of gender nonconforming youth. Pediatrics, 134, 1184-1192. doi:10.1542/peds.2014-0772

Villarruel, A. M., Loveland-Cherry, C. J., \& Ronis, D. L (2010). Testing the efficacy of a computer-based parent-adolescent sexual communication intervention for Latino parents. Family Relations, 59, 533-543. 
Villarruel, A. M., Zhou, Y., Gallegos, E. C., \& Ronis, D. L. (2010). Examining long-term effects of Cuídate-a sexual risk reduction program in Mexican youth. Pan American Journal of Public Health / Revista Panamericana de Salud Pública, 27, 345-51.

Wartella, E., Rideout, V., Montague, H., Beaudoin-Ryan, L., \& Lauricella, A. (2016). Teens, health and technology: A national survey. Media and Communication (ISSN: 21832439), 4, 13-23 doi: 10.17645/mac.v4i3.515

Watt, M., Rancourt, D., Cousineau, T. M., \& Franko, D. L. (2005). Trouble on the Tightrope: An interactive body image program for middle schoolers. Journal of Nutrition Education and Behavior, 37, 211-212.

Wellings, K., \& Parker, R. (2006). Sexuality education in Europe - A reference guide to policies and practices. IPPF European Network. Retrieved from https://hivhealthclearinghouse.unesco.org/library/documents/sexuality-education-europereference-guide-policies-and-practices

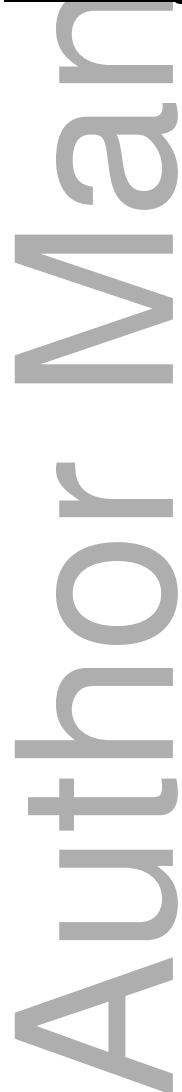

This article is protected by copyright. All rights reserved 